\title{
A centralidade em educação e em saúde básicas: a estratégia político-ideológica da globalização ${ }^{1}$
}

Ireni M arileneZago Figueiredo*

Resumo: N o contexto da globalização, a concepção de crescimento/desenvolvimento está orientada na direção do mercado e da competitividadeinternacional, sustentada por políticas deajusteeconômico quetêm produzido um quadro considerável de exclusão social. Diante dessecenário, que representa umaameaça à estabilidadedo sistema, os organismosinternacionais, o FM I, o Banco Internacional para a Reconstrução eD esenvolvimento (BIRD)/Banco M undial eo Banco Interamericano deD esenvolvimento (BID ), têm al ertado os governos sobrea gravidade do problemaeenfatizado a necessidade deintervenção, por partedo Estado, em serviços sociais como a educação ea saúd le básicas. N esteartigo, sustentamos que ênfase na educação ena saúde bási cas ép parteintegrantedas estratégias político-ideológicas da gl obalização e, portanto, constituem-seem variáveisfundamentaisno processo deimplementação das políticas deajuste econômico paramanter a pobreza em níveissuportáveis, contribuindo, assim, para a estabilidade política esocial.

Palavras-chave: desenvolvimento; globalização; políticas deajusteeconômico; educação; saúde.

Abstract: In the context of globalization, the conception of growth/development is oriented towards the market and international competitiveness, which, in its turn, is supported by economic adjustment policiesthat have produced a considerablesocial exclusion environment. In face of this situation, which has been threatening the system stability, the international organisms, theIM F, thel nternational Bank for Reconstruction and D evelopment (IBRD )/ World Bank and thelnter-American D evelopment Bank (ID B), have alerted thegovernments on the seriousness of the problem and emphasized theneed for State intervention in social services such as basic education and health. In this article, we state that focusing on basic education and health isan important part of the political ideological strategiesin globalization and, therefore, they are vital variablesin theprocess of implementation of economic adjustment policies to keep poverty at bearable levels, contributing, thus, for social and political stability.

Key words: devel opment; globalization; economic adjustment policies; education; health.

\footnotetext{
* Professora do Colegiado do Curso de Pedagogia e do Mestrado em Educação da Unioeste Universidade Estadual do Oeste do Paraná - Campus de Cascavel - PR. Pesquisadora do Grupo de Estudos e Pesquisas em Política Educacional e Social - GEPPES. irenifigueiredo@ unioeste.br

1. Este texto é resultado de parte das reflexões sistematizadas para comprovação da tese de doutorado defendida na Faculdade de Educação da Unicamp, área de concentração História, Filosofia e Educação, sob orientação da Profa. Dra. Maria Elizabete Sampaio Prado Xavier.
} 
No contexto do Pós-Segunda Guerra, foi produzida a Ideologia D esenvolvimentista, como estratégia da afirmação da hegemonia econômica e política dos EUA e do deslocamento da Guerra Fria para o chamado Terceiro M undo. A Guerra Fria, sustentada pela D outrina Truman, foi apresentada pelos EUA que, entre outros objetivos, visava ajudar financeiramente os países que decidissem lutar contra o comunismo (Teixeira, 1993).

A M ensagem que Truman enviou ao Congresso, em junho de 1949, conhecida como "Ponto IV", enfatizou a necessidade de ajuda às economias subdesenvolvidas, para ampliar as condições de trocas econômicas entre os EU A e esses países. Em 1950, foi outorgado o Act for International Development Ato para o Desenvolvimento Internacional ou "Ponto IV", legalizando as já legitimadas determinações da M ensagem enviada por Truman ao Congresso em 1949, traçando as bases e as noções para o desenvolvimento econômico dos países subdesenvolvidos. D efinia-se, portanto, o projeto de segurança externa frente às possíveis investidas dos países comunistas nos países periféricos. "Estabelecia, aí, novas regras para a cooperação econômica, mediante 0 estabelecimento de acordos para a assistência econômica, para a cooperação financeira, técnica e para as doações" (Nogueira, 1999, p. 63).

A "Política da Porta Aberta" indicou a direção da política de segurança externa dos EU A, construindo a noção da inexorabilidade da assistência técnica para o crescimento econômico, desde a M ensagem de Truman, o "Ponto IV". O s objetivos da política de segurança externa norte-americana foram colocados em prática através da mediação da Agência Norte-Americana para 0 D esenvolvimento Internacional - USAID (1958), que ganhou destaque no Brasil a partir de 1961, com a promulgação da "Carta Punta del Este". D esse modo, em agosto de 1961, na reunião do Conselho Interamericano Econômico e Social (CIES-OEA), realizada em Punta del Este, U ruguai, as Repúblicas Americanas subscreveram a Carta Punta del Este, conferindo o caráter interamericano à Aliança para o Progresso, proposta pelo governo J ohn K ennedy (D eitos, 2001).

D essa forma, nas primeiras décadas do Pós-Segunda Guerra, as ajudas bilaterais para o desenvolvimento preponderaram em relação às ajudas multilaterais, pois o Banco M undial, inicialmente, teve suas ações mais voltadas para a reconstrução física e econômica dos países da Europa, com o Plano $\mathrm{M}$ arshall. N a América Latina, no contexto da Guerra Fria, tivemos o programa da Aliança para o Progresso, que à semel hança do que fora feito na Europa, por intermédio do Plano $\mathrm{M}$ arshall, tinha como objetivo promover o desenvolvimento nessa região.

Toda a formulação da Aliança para o Progresso, no período da ideologia do desenvolvimento, está associada ao comunismo e, conseqüentemente, ao tema 
da segurança, pois a preocupação com as tensões sociais, como resultado da pobreza, está associada a essa ideologia.

No contexto da Aliança para o Progresso, a educação e a saúde não foram consideradas as principais estratégias de intervenção. A educação, por exemplo, foi pensada menos em termos econômicos, relacionada ao desenvolvimento, e mais como espaço de embates ideológicos, pois havia grande preocupação com a influência marxista nas universidades latino-americanas. No contexto da Aliança para o Progresso, a educação foi pensada mais a partir de T. W. Schultz, mas a estratégia da Aliança é completamente rostowiana. N este sentido,

\begin{abstract}
para a perspectiva neoclássica, sistematiza por T. W. Schultzna teoriado capital humano, aEducação seria "o" fator chaveque levaria os países insuficientemente desenvolvidos ao desenvolvimento. Como é possível observar, este tipo de proposição tem importantes nuances em relação às teses de Rostow, por acentuar a ação ideológica. N esta época, ambas orientações coexistiam nos centros de poder. Apesar de convergirem quanto à necessidade de interferência "externa" [...], divergiam quanto ao caráter da interferência externa: a primeira enfatizava quea educação ea técnica (necessariamente exógenas) poderiam al avancar o desenvolvimento, a segunda sustentava a combinação de ações ideológicas e ações de domínio direto e aberto. A história mostrou que no período áureo de desenvolvimentismo, prevaleceu a segunda, como atesta a terrível série de gol pes militares na América Latina... (Leher, 1998, p. 72).
\end{abstract}

Portanto, até a década de 1960, a educação e a saúde eram secundárias para o Banco M undial. A situação começou a mudar a partir de George D. Woods e, mais definitivamente, na gestão de Robert S. M cN amara (1968-1981), que deu ênfase à pobreza. "O foco na pobreza significava o fortalecimento de uma concepção estratégica diferente da de Johnson e Rostow e, por conseguinte, da Aliança para o Progresso" (Leher, 1998, p. 202).

N a gestão de M cN amara, as sugestões do Relatório Pearson (1969), que constituíram o resultado de um estudo sugerido pelo seu antecessor G eorge D. Woods (1963-1968), foram viabilizadas. As conclusões do Relatório Pearson não foram mais do que a identificação das práticas propostas por Truman, em sua M ensagem, em 1949. O Relatório sistematizou as recomendações decorrentes da avaliação das conseqüências da ajuda para o desenvolvimento econômico, sendo que o caráter de crise e de desencantamento da ajuda para 0 desenvolvimento, da parte dos países desenvolvidos, foi atribuído à ajuda bilateral (N ogueira, 1999). 
$\mathrm{N}$ a década de 1970, portanto, a ênfase do BIRD nos investimentos sociais estava associada às críticas e recomendações do Relatório Pearson, e também à crise internacional e aos movimentos de libertação na África, na Ásia ena América Latina. Assim, foi a partir da conjuntura de crise internacional e das questões de segurança implícitas que o Banco Mundial passou a considerar as causas sociais da pobreza e das necessidades básicas.

$\mathrm{N}$ essa direção, M cN amara representou o primeiro marco expressivo de mudança na concepção teórica do Banco M undial, pois anteriormente essa instituição nunca havia concebido a tarefa de desenvolvimento como algo relacionado ao alívio da pobreza. $D$ efendeu que a pobreza deveria ser enfrentada, uma vez que os benefícios do crescimento econômico por si só não alcançariam os pobres. Foi, portanto, um dos principais responsáveis pela mudança na estratégia de política externa norte-americana.

D essa forma, a noção de desenvolvimento tem sido referência histórica para o Banco M undial. A ênfase no crescimento econômico, como dinamizador do desenvolvimento, tem sido a base conceitual desde a sua origem. Essa noção de crescimento/desenvolvimento e as transformações construídas no decorrer de sua história estão relacionadas ao movimento do capitalismo em nível internacional e suas relações com os países periféricos, materializadas por meio de diferentes articulações e mediações político-ideológicas e econômicofinanceiras, na implementação dos programas de desenvolvimento e de ajustes estruturais e setoriais empreendidos nesses países.

0 financiamento concedido pelo Banco $M$ undial, até o final da década de 1950, destinou-se aos setores de infra-estrutura de capital, tais como: transportes, energia elétrica, telecomunicações, irrigação e racionamento de água. No início da década de 1960, o Banco e a AlF reconheceram que 0 desenvolvimento de setores como a educação, a agricultura e a indústria teriam importância decisiva para o progresso social e econômico. 0 Banco e a AIF, em 1968, empreenderam o primeiro plano qüinqüenal, no qual as operações creditícias duplicaram em comparação com os cinco exercícios anteriores. Além do financiamento para os setores tradicionais, incrementaram-se, em medida significativa, as operações relacionadas com os setores educativo e agrícola. Também se prestou mais atenção aos aspectos sociais do progresso econômico, incluindo o crescimento da população, o emprego, a saúde, a desnutrição, os efeitos ambientais... (Banco M undial, 1974).

Portanto, com M cN amara, a concepção do desenvolvimento não se limitou ao crescimento econômico. A partir desse momento, o Banco M undial sustentou que 0 crescimento econômico precisaria incluir aspectos sociais e políticos, associados à planificação familiar, à urbanização e ao desemprego. M cN amara (1974) defendia que os governos deveriam reorientar sua política de 
desenvolvimento para enfrentar frontalmente a pobreza. O s governos real izariam essa meta sem abandonar os objetivos do crescimento econômico geral, mas deveriam estar dispostos a dar alta prioridade ao estabelecimento de metas de crescimento em termos de necessidades humanas básicas: educação, saúde, nutrição, habitação e emprego.

0 atendimento à educação e à saúde básicas constitui-se, com clareza indiscutível, em estratégias político-ideológicas para conter o crescimento populacional e, conseqüentemente, administrar a pobreza. 0 Relatório Pearson atribuía ao crescimento demográfico descontrolado o aumento da pobreza, 0 que foi reafirmado por M cN amara (1974, p. 18), ao ressaltar que "[...] o maior obstáculo ao progresso social e econômico da maior parte dos povos do mundo subdesenvolvido é o crescimento demográfico desmesurado".

O Relatório Pearson vinha rever a noção de desenvolvimento e suas relações com 0 crescimento econômico. Assim, a preocupação com a "satisfação das necessidades básicas" emergiu das recomendações e indicações deste Relatório, passando a associar o financiamento de infra-estrutura ao financiamento da "satisfação das necessidades humanas básicas". Todavia, o setor de infra-estrutura, na concessão dos financiamentos, permaneceu como eixo central para conquistar o crescimento econômico, fator de desenvolvimento (D eitos, 2001; Lichtensztejn; Baer, 1987; N ogueira, 1999).

$\mathrm{N}$ esse sentido, para conter a pobreza eram precisos investimentos em infraestrutura produtiva e social, educação, saúde, moradia, controle demográfico, nutrição e criação de empregos. M as também era preciso conceber a educação e a saúde de forma integrada para garantir a estabilidade social, com 0 desenvolvimento de projetos, nessas áreas, que articulassem o crescimento/ desenvolvimento com o bem-estar social. D essa forma, o Banco M undial (1975) considera que a saúde contribui diretamente com o bem-estar humano e pode ser considerada como uma medida de bem-estar social. U ma política de saúde construtiva deve almejar a manutenção do delicado equilíbrio entre uma saúde melhor e o desenvolvimento econômico geral. As atividades no setor de saúde devem focalizar-se nas atividades do setor da educação, devendo apoiar projetos que combinem a promoção do desenvolvimento econômico com a redistribuição do bem-estar.

A "satisfação das necessidades básicas", na estratégia do Banco M undial, expressava-se no reconhecimento de que, por intermédio do crescimento econômico, não seria automaticamente alcançado o bem-estar da maioria da população dos países subdesenvolvidos. Nos vinte anos de "ajuda para 0 desenvolvimento", constatou-se que o bem-estar social da população não teria correspondido ao índice de crescimento, medido pelo Produto Bruto dos países razoavelmente industrializados, como foi o caso do Brasil. A suposição era de 
que o desenvolvimento social ocorreria como derivação mecânica do crescimento econômico. Como essa lógica não se realizou, atribuiu-se ao crescimento demográfico descontrolado o aumento da pobreza e, conseqüentemente, a não ampliação dos benefícios sociais do progresso, produto dos índices do crescimento econômico (N ogueira, 1999).

N a Aliança para o Progresso a educação não fez parte do "núcleo sólido" de sua formulação e ocupou apenas um lugar secundário, ainda que, do ponto de vista político, a U niversidade tenha sido considerada relevante como espaço de embates ideológicos. Porém, com o reconhecimento do papel fundamental da agricultura e do capital humano - uma preocupação constante do Banco M undial - consagrar-se-iam as teses neoclássicas de T. W. Schultz, da Teoria do Capital H umano, em que a educação e a técnica (necessariamente exógenas) poderiam impulsionar o desenvolvimento, levando os países subdesenvolvidos ao desenvolvimento (Leher, 1998).

A formação do "capital humano" requeria investimentos em educação e saúde, os quais reduziriam a pobreza e gerariam o bem-estar social. Assim, era preciso promover a "satisfação das necessidades básicas" a partir de dois processos: aumentar a produtividade dos mais pobres, por meio da "val orização" do "capital humano", e promover a extensão de serviços básicos mínimos a essa população.

N esse sentido, enfatiza M cN amara (1979), a população pobre necessita de um nível adequado de renda, bem como de um acesso eqüitativo aos serviços públicos essenciais que são fundamentais para sua saúde e produtividade. Os serviços públicos essenciais contemplariam o abastecimento de água potável, a educação básica, a atenção médica preventiva, a eletricidade e o transporte público. A tarefa do Banco Mundial consiste em ajudar os países-membros em desenvolvimento na realização de todas as suas atividades relacionadas com 0 processo de desenvolvimento. I sso inclui a luta contra a pobreza absoluta, visto que a única esperança viável de reduzir a pobreza consiste em ajudar as pessoas pobres a incrementar sua produtividade.

A educação e a saúde básicas passavam a ser amplamente consideradas variáveis fundamentais do processo de desenvolvimento social e econômico e de segurança externa. $\mathrm{N}$ a Conferência Internacional sobre Atenção Primária em Saúde, realizada em Alma-Ata, U RSS, em setembro de 1978, com patrocínio conjunto da O MS - O rganização M undial de Saúde - e do U N ICEF - Fundo das $\mathrm{N}$ ações U nidas - , afirmou-se que um dos principais objetivos dos governos, das organizações internacionais e da comunidade mundial, até o ano 2000, é que todos os povos atinjam um nível de saúde que lhes permita levar uma vida social e economicamente produtiva.

Assim, a promoção e a proteção da saúde são condições indispensáveis para um determinado desenvolvimento econômico e social sólido, bem como 
contribuiriam para melhorar a qualidade de vida e para alcançar a paz social. A atenção primária em saúde é a chave para alcançar essa meta como parte do desenvolvimento. U ma política de independência, de paz e de desarmamento deveria liberar recursos adicionais, os quais poderiam ser empregados para fins pacíficos e, em particular, para acelerar o desenvolvimento social e econômico. U ma proporção desses recursos deveria ser destinada ao cuidado primário com a saúde, elemento essencial do desenvolvimento (O M S/U nicef, 1978).

0 enfoque do Banco Mundial na educação ampliou-se no final da década de 1960, acabando por destacá-la como uma de suas políticas setoriais durante a década de 1970. N esse contexto, a UNESCO foi perdendo suas atribuições para o Banco Mundial e, após a saída dos EUA daquele organismo, em 1984, 0 debate sobre a educação foi se transformando em assunto de negócios, de banqueiros e de estrategistas políticos. A saída dos EU A da UNESCO situouse no bojo do abandono da ideologia do desenvolvimento e de privilegiamento de outros meios de direção intelectual e moral presentes na ideologia da globalização, que surgiu a partir da crise estrutural do capitalismo, já evidenciada na década de 1970. Dessa forma, a doutrina desenvolvimentista estava demasiadamente exaurida e desacreditada. Por isso, foi muito bem-vinda a renovação do sistema ideológico. O s neoliberais consideram-se como portadores da "verdadeira doutrina" capitalista e empreenderam reformas que configuram, conforme alegam, uma nova Era, a da globalização (Leher, 1998).

D essa forma, antes da década de 1970, os empréstimos do Banco M undial foram direcionados para o setor de infra-estrutura (energia, transportes e comunicações). A partir da década de 1970, com projetos destinados ao setor social (Tabelas 1 e 2), teve início uma outra fase de atuação do Banco M undial nos países subdesenvolvidos.

Tabela 1. Brasil - empréstimos com o BIRD para o setor social 1949-1989

\begin{tabular}{|c|c|}
\hline Períodos & Setor Social \\
\hline $1949-1959$ & - \\
\hline $1960-1969$ & - \\
\hline $1970-1979$ & $14,7 \%$ \\
\hline $1980-1989$ & $18,7 \%$ \\
\hline $1949-1989$ & $16,9 \%$ \\
\hline
\end{tabular}

Fonte: G onzalez et al., 1990

As conseqüências da crise financeira internacional e da crise da dívida externa (1982) que atingiram os países periféricos, decorrentes da associação da elevação 
do preço do petróleo (1973-1979); da ação unilateral dos EUA de elevar as taxas de juros (1979) e da revalorização do dólar pelo Banco Central norteamericano (1979), contribuíram para que os organismos multilaterais de financiamento, o FM I, o BIRD e o BID, assumissem a liderança no processo de renegociação da dívida desses países, por meio de uma série de condicionalidades econômico-financeiras e político-ideológicas circunscritas aos Planos de Estabilização e aos empréstimos para os ajustes estruturais (1980) e setoriais (1983).

Assim, com a queda do M uro de Berlim e o fim da Guerra Fria, o BIRD já não precisava mais lutar para conter a expansão do comunismo. Foi assim que iniciou a sua contribuição para a expansão do novo modelo econômico, conforme desejavam e pressionavam os governos conservadores dos países centrais. Os EUA abandonaram a doutrina de desenvolvimento para todos, a partir da crise da dívida externa, concentrando-se na defesa de que os países pobres deveriam economizar tanto quanto possível, para honrar os serviços de suas dívidas e preservar o seu crédito (Leher, 1998).

As ações do presidente do Banco M undial, Alden W. Clausen (1981-1986), voltaram-se para 0 ajuste estrutural das economias endividadas. N essa direção, os países em desenvolvimento deveriam ajustar-se à economia externa por meio dos programas de ajuste econômico. Alden W. Clausen também sustentou que a estratégia para a redução da pobreza estaria no aumento da produtividade dos pobres. Os governos deveriam adotar medidas para assegurar que as oportunidades de emprego e o poder aquisitivo dos pobres não fossem limitados pela doença, pela insuficiência alimentar e pela carência de educação (Clausen apud Silva, 2002).

N esse sentido, na década de 1980, para dar continuidade ao processo de implementação das políticas de ajuste econômico, houve uma ampliação dos recursos para os setores sociais (Tabela 2). Essa prioridade do BIRD estava associada à necessidade de controlar as situações de extrema pobreza durante 0 processo de ajustamento econômico, enquanto medida para evitar possíveis tensões sociais. Em 1984, a educação e a saúde obtiveram 30,49\%, do total de empréstimos. Em 1988, a saúde, o desenvolvimento urbano, o abastecimento de água e o saneamento básico representaram 58,01\% do total dos investimentos, e em 1989 o desenvolvimento urbano obteve 100\% dos empréstimos.

N a gestão de Barber Conable (1986-1991), os empréstimos do Banco M undial vieram acompanhados das condicionalidades impostas pelos ajustes estruturais e setoriais. $\mathrm{N}$ a conjuntura da crise, com os empréstimos de ajuste setorial e estrutural, permaneceu a noção de que para haver desenvolvimento era preciso haver crescimento econômico, mas foi nesse contexto que 0 crescimento se orientou para a imersão competitiva no mercado internacional. 
Tabela 2. Brasil - empréstimos do BIRD ao setor social 1949-1989

\begin{tabular}{|c|c|c|c|c|c|}
\hline \multicolumn{7}{|c|}{ Setor Social } \\
\hline Anos & Educação & Saúde & $\begin{array}{c}\text { População } \\
\text { e N utrição }\end{array}$ & $\begin{array}{c}\text { D esenvolvimento } \\
\text { Urbano }\end{array}$ & $\begin{array}{c}\text { Abastecimento } \\
\text { de Água e } \\
\text { Saneamento }\end{array}$ \\
\hline 1970 & - & - & - & - & - \\
\hline 1971 & $3,32 \%$ & - & - & - & $13,43 \%$ \\
\hline 1972 & - & - & - & - & - \\
\hline 1973 & - & - & - & - & - \\
\hline 1974 & $15,13 \%$ & - & - & - & $26,39 \%$ \\
\hline 1975 & - & - & - & - & - \\
\hline 1976 & - & - & $5,30 \%$ & - & $11,16 \%$ \\
\hline 1977 & $11,98 \%$ & - & - & - & - \\
\hline 1978 & - & - & - & - & $8,87 \%$ \\
\hline 1979 & - & - & - & $32,88 \%$ & $20,17 \%$ \\
\hline 1980 & $5,4 \%$ & - & - & - & $45,40 \%$ \\
\hline 1981 & - & $1,17 \%$ & - & - & $16,22 \%$ \\
\hline 1982 & - & - & - & $12,38 \%$ & $3,25 \%$ \\
\hline 1983 & $0,98 \%$ & - & - & $2,59 \%$ & $14,83 \%$ \\
\hline 1984 & $12,77 \%$ & $17,72 \%$ & - & - & - \\
\hline 1985 & - & $0,13 \%$ & - & - & $1,07 \%$ \\
\hline 1986 & - & $3,62 \%$ & - & $10,93 \%$ & - \\
\hline 1987 & $5,35 \%$ & - & - & - & $3,59 \%$ \\
\hline 1988 & - & $17,37 \%$ & - & $27,89 \%$ & $12,75 \%$ \\
\hline 1989 & - & - & - & $100 \%$ & - \\
\hline
\end{tabular}

Fonte: G onzalez et al., 1990

$\mathrm{N}$ a década de 1990, o Banco $\mathrm{M}$ undial reafirmou a necessidade de administrar a pobreza, ao destacar que seu objetivo continuava sendo a sua redução. 0 argumento pautava-se na defesa de que o ajuste era visivelmente necessário para conquistar a saúde a longo prazo (Banco Mundial, 1993, p. 08). D esse modo, permaneceu a ênfase no crescimento econômico como fator de desenvolvimento social, ao declarar que suas ações consistiam em colaborar com os países, ajudando-os a formular e aplicar políticas que resultassem na ampliação dos mercados e no fortalecimento de suas economias, visando 
melhorar a qualidade de vida de todos os habitantes (Banco M undial, 1995b; p.9; 1995d, p.VI apud Silva, 2002, p.82).

Com Lewis T. Preston (1991-1995), evidenciou-se uma nova condicionalidade aos empréstimos do Banco Mundial, dado que a governabilidade constituiria um critério fundamental para a obtenção de êxito nas reformas. A ênfase na governabilidade estaria associada à capacidade do governo de realizar as políticas de ajuste, definidas pelos organismos internacionais. Assim, a ênfase na "administração da pobreza" dizia respeito às condições de governabilidade e, mais genericamente, à sustentação das reformas.

0 presidente do Banco M undial, J. D. Wolfensohn (1995), apontou para a mesma direção, sendo mais explícito ao associar pobreza e segurança. D estacou, portanto, que a redução da pobreza seria prioridade, visto que ela era responsável por gerar instabilidade política, social e econômica. O Banco M undial estava ciente do problema, e daí a preocupação com a governabilidade, em duas dimensões: 1) criar condições macroeconômicas estáveis para manter inalteráveis as regras contratuais relativas ao capital e ao trabalho; e2) controlar as tensões sociais decorrentes da "exclusão forçada", visando a estabilidade política (Leher, 1998).

Foi no último período que se produziu um consenso, no interior do Banco Mundial, sobre os danos sociais e o fracasso da aplicação dos Planos de Estabilização do FM I e dos programas de ajuste do BIRD e do BID . O s prejuízos dos programas de ajustes foram mencionados no documento World $D$ evelopment Report, de 1990, quando admitiu que, "no curto prazo, alguns pobres podem perder", e em 1993, quando Sebastian Edwards, economista-chefe para América Latina e Caribe, reconheceu que em alguns países os programas de ajuste estrutural eram excessivamente custosos, o que piorava a distribuição de renda, embora o custo de não realizar também fosse alto. O utros estudos do Banco M undial também reconheceram que em muitos países em processo de "ajuste" houvera aumento de desemprego, enquanto a matrícula no ensino primário e os níveis nutricionais dos pobres desabaram. A política que visava "aliviar" a pobreza teria de ser incluída no contexto da política de "ajuste estrutural" (Leher, 1998).

A necessidade de dar resposta imediata aos grupos socialmente vulneráveis, com programas para os pobres (pro-poor programs), do Banco Mundial, está sistematizada no documento World Development Report 1990: Poverty, que descreve os indicadores do agravamento da pobreza produzido pela crise, somado aos efeitos das políticas de ajuste econômico. A necessidade de administrar a pobreza e de controlar politicamente a miséria tem sido ampliada, consistindo num mecanismo estratégico de longo prazo, o que levou à publicação dos dois volumes da U N ICEF sobre o AdjustmenteW ith a H uman Face (1987), e também do documento Reforma social e pobreza (1993), organizado e publicado 
conjuntamente pelo BID e pelo PN UD. Em 1999 o FM I também demonstrou sua "preocupação" com aquilo que chamou de "humanização da globalização", conforme declaração do ex-diretor da instituição, M ichael C andessus, para 0 jornal Folha de São Paulo, em 29 de setembro (Tavares; Fiori, 1993; Soares, 2002).

Para o Banco M undial, o atendimento à educação e à saúde básicas, como estratégias para administrar a pobreza e inserir o indivíduo no mercado de trabalho, é inerente ao cumprimento da "satiffação das necessidades básicas" estabelecidas por Robert S. M cN amara, no final da década de 1960 e consolidadas a partir da década de 1970. N a década de 1990, observamos essa preocupação quando o Banco M undial estabeleceu que cabe à educação básica fornecer conhecimentos técnicos sobre nutrição, sobre controle da natalidade, sobre programas de contabilidade, de informática e de conhecimentos sobre ecologia para evitar a degradação ambiental e manter a força dinâmica do trabalho saudável (Banco Mundial, 1998-1999).

Especialmente na década de 1990, a concepção de trabalho, para o Banco M undial e para o BID , constituiu o maior bem dos pobres; noção fundamental para justificar o investimento em capital humano. Concebe-se que a pobreza se reduz à medida que aumenta 0 nível de educação da força de trabalho. Isso legitima a prioridade da educação e da saúde básicas, o que, segundo o Banco M undial e o BID, além de possibilitar a obtenção de renda pelos pobres, impulsionará o crescimento econômico e o desenvolvimento social, reduzindo a pobreza.

A educação e a saúde articulam-se como mitos promotores, na relação educação/saúde-trabalho-renda-redução da pobreza. Os organismos multilaterais de financiamento sustentam, portanto, que melhorar a educação é de particular importância para consolidar o desenvolvimento econômico e social (BID, 1999). A educação constitui um instrumento de promoção do crescimento econômico e de redução da pobreza, mediante a utilização produtiva do trabal ho e a prestação de serviços sociais básicos aos pobres (Banco M undial, 1995). N a área da saúde, é fundamental a intervenção pública como condição para reduzir ou aliviar a pobreza, bem como para melhorar as condições de saúde e contribuir com o crescimento econômico (Banco M undial, 1993).

A ênfase na educação e na saúde básicas, como mecanismo de reduzir a pobreza por meio do aumento da produtividade e da renda, resultaria numa situação de bem-estar social dos indivíduos. Dessa forma, o Banco M undial (1993) sustentava que os investimentos públicos na área da saúde se justificavam na medida em que os pobres nem sempre podiam pagar pelo tratamento médico, que resultaria no aumento de sua produtividade e seu bem-estar. Esses investimentos são importantes, pois reduzem a pobreza ou mitigam suas 
conseqüências. Assim, algumas ações em favor da saúde são de caráter essencialmente público.

$\mathrm{N}$ a América L atina, a implementação de um conjunto de reformas estruturais e setoriais de dimensão neoliberal, realizadas nas duas últimas décadas, tem produzido um quadro de distribuição de renda desigual, que gera a pobreza, seguida da precarização das condições de saúde, educação, moradia e emprego. Assim, as mudanças efetivadas na noção de crescimento/desenvolvimento, conforme mencionamos, e as ações que foram realizadas a partir dessas novas noções, pelo Banco M undial, demonstram que, mesmo com a incorporação de outros fatores, o crescimento econômico continuou sendo a meta prioritária para o desenvolvimento social dos países periféricos. 0 FM I, o Banco M undial e o BID, ao prosseguirem com o processo de implementação das políticas de ajuste estruturais e setoriais, buscam corrigi-las com medidas destinadas a administrar a pobreza.

N este sentido, a preocupação com 0 aumento da pobreza e o consenso no interior das instituições, como o FM I, o BID e o Banco M undial, de que havia necessidade de correção nas propostas de ajuste não encerraram a agenda para a implementação dos programas de ajustes estruturais e setoriais. A necessidade de intervir, de acordo com o Banco M undial (1993), é porque há necessidade de proteger os pobres, visto que ainda resta muito a aprender acerca de meios mais eficazes de implementar os programas de estabilização e de ajuste.

Afinal, destaca o Banco Mundial (2000), o Brasil, no geral, aceita a globalização como realidade e quer tirar o máximo de benefício dela. Ao mesmo tempo, os riscos e custos de resultados negativos, especialmente no âmbito social, precisam ser cuidadosamente gerenciados.

Considerando a dívida externa brasileira, nos últimos 30 anos (1968-1999) cresceu 237 bilhões de dólares! No decorrer do primeiro mandato de FH C, a transferência para os credores girou em torno de 128 bilhões de dólares, cerca de 233 bilhões de reais. Com esse dinheiro teria sido possível pagar um "bônus" de 1.474 reais para cada brasileiro, ou dar 45 mil reais para cada família brasileira que vive com até 1 salário mínimo, ou investir 58 bilhões de reais ao ano para erradicar a pobreza, durante quatro anos (G onçalves; Pomar, 2001).

N o entanto, no Brasil na década de 1990, dados demonstram que o número de pobres ${ }^{2}$ era de 39,3 milhões, correspondente a $27 \%$ da população total.

2. A estimativa do número de pobres aqui está baseada em dados da PNAD-90. São consideradas pobres aquelas pessoas cujo rendimento familiar per capita mensal é igual ou inferior ao valor de uma linha de pobreza (1/4 do salário vigente em 1980). Este valor da linha de pobreza correspondia a um rendimento familiar per capita anual de US\$ $413 \mathrm{em} 1990$, o equivalente a US\$34,4 mensais...» Nota da autora no texto. 
N essa mesma década, trinta e dois milhões de pessoas (22\% da população brasileira), compondo nove milhões de famílias, estariam em situação de indigência ${ }^{3}$, com semelhante distribuição regional e urbano-rural (Soares, 2001).

Também é preciso lembrar que os diversos ajustes fiscais têm implicado cortes para o conjunto das políticas sociais, inclusive para as políticas sociais restritas e focalizadas.

\begin{abstract}
Em termos deevolução do gasto com o conjunto dosbenefícios assistenciais dirigidosaosmaispobres, osanosiniciais da década de 1990 confirmam eagravam a tendência anterior dequeda, apresentando cortes de $50 \%$ nesses gastos. 0 s recursosrelativos aosgastos com salário-família passam deum patamar deU S 1 bilhão entre 1980 e 1982 paraum patamar de 100 milhõesa partir de 1991 (D ain, 2001, p.133).
\end{abstract}

A racionalidade econômica (relação custo-benefício) é o parâmetro para definir as prioridades de investimentos em educação e saúde e, conseqüentemente, a taxa de retorno social a elas inerentes.

0 acesso à água potável eo controle de doenças infecciosas são bens e serviços públicos com grandes externalidades ${ }^{4}$ que 0 setor privado não podefornecer, ou só o faz demaneiralimitada [...] A rentabilidade da educação é especialmente el evada no nível primário, porquea alfabetização universal gera grandes external idades para a sociedade. A educação das meninas, por exemplo, estávinculadaà mel horia da saúde das mulheresede seusfilhoseataxas mais baixas defecundidade (Banco M undial, 1997, p.55).

O s impactos e as conseqüências da crise estrutural do capitalismo, da crise da dívida externa e dos ajustes estruturais e setoriais, que produziram respostas sociais e políticas específicas, têm como resultado a priorização de ações de assistência focalizadas e restritas, com ênfase nas áreas de educação e saúde básicas. Para tanto, a defesa tem sido de que é preciso "...melhorar a eficiência do gasto social e apoiar a descentralização dos serviços oficiais, com vistas a parcerias estreitas com a comunidade e a sociedade civil" (BID, 2000, p.216).

3. Ver IPEA, 1993, que considera indigentes aquelas famílias cujos rendimentos mensais thes permitem, no máximo, a aquisição de uma cesta básica de alimentos. Nota da autora no texto.

4. O Banco Mundial (1993) define o que geraria essas externalidades positivas da seguinte forma: os bens públicos são caracterizados pelo fato de que todos podem usá-los ou beneficiar-se deles, sem que tais uso e benefício fiquem limitados para os demais. As externalidades positivas dos bens públicos ocorreriam, portanto, quando o consumo de um indivíduo beneficiasse aos demais. Por isso, é justo que o pacote de atendimento clínico essencial seja financiado com verbas públicas, na medida em que gera externalidades positivas e reduz a pobreza. 
Em síntese, no contexto da ideologia da globalização, as políticas restritas e compensatórias, que têm como prioridade atender aos grupos de extrema pobreza, consubstanciam, em parte, a proposta dos organismos multilaterais de financiamento - em especial o Banco M undial e o BID - de focalização dos gastos destinados a esses grupos, o que justifica o investimento do Estado nas áreas de educação e saúde básicas.

$N$ esse sentido, a lógica emergencial e seletiva dos programas que reforçam essa perspectiva vincula-se, por exemplo, às ações das 0 rganizações $N$ ãoGovernamentais (O N G s), do Programa dos Agentes Comunitários de Saúde (PACS), do Programa de Saúde da Família (PSF), do Programa Fome Zero, do Programa Bolsa Família, do Programa Comunidade Solidária, entre outros.

$O$ consenso do BID e do Banco Mundial, quanto ao Estado oferecer os serviços essenciais básicos, de educação e de saúde, tem como meta manter a pobreza em níveis suportáveis, atendendo às demandas sociais críticas para administrar os efeitos recessivos das duras políticas de ajuste econômico. D esse modo, pode-se afirmar que a interven ção do Estado, nessas áreas, contribui para criar as condições favoráveis mínimas para implementar as políticas de ajuste econômico, visando contribuir com a estabilidade política e social (Figueiredo, 2006).

\section{Referências bibliográficas}

BAN CO M U N DIAL. Cem países doisbilhõesdeseres A dimensão do desenvolvimento. Rio de Janeiro: Fundação G etúlio Vargas, Serv. de Publicações, 1974.

BAN CO M U N D IAL. Educación. D ocumento dePolítica Sectorial. Washington, D.C., 1975.

BAN CO M U N D IAL. Education. Politique sectorielle. 3.ed. Washington, D.C., 1980.

BAN CO M U N DIAL. Prioridadesy estrategiaspara la educación: estudio sectorial del Banco M undial. Versão Preliminar. Washington, D.C. M ayo, 1995.

BAN CO M U N D IAL. Relatório n.20160-BR. Washington, D .C ., 6 demarço de 2000. In: BARROS, F. (org.). A sestratégias dos bancosmultilateraispara o Brasil (2000-2003). B raślia: RedeBrasil sobreInstituiçõesFinanceiras M ultilaterais, 2001.

BAN CO M U N DIAL. Relatório sobre o desenvolvimento mundial de 1993: investindo em saúde. Rio de aneiro: FGV, 1993.

BAN CO MUNDIAL. O Estado num mundo em transformação. Relatório sobre 0 desenvolvimento mundial. Washington, 1997.

BID . Brasil. D ocumento dePaís. Versão Final. (GN -2104-1). Washington, D .C., 7 de julho de 2000. In: BARROS, F. (org.). As estratégias dos bancos multilaterais para o Brasil (20002003). Brasília: RedeBrasil, 2001.

D AIN , S. 0 financiamento público na perspectivada política social. Revisa Economia eSociedade (17), p.113-140, dez. 2001. 
DEIT OS, R. A. 0 capital financerro ea educação no Brasil. 2005. Tese(D outorado em Educação). Faculdade deEducação. U niversidade Estadual de C ampinas- Unicamp, C ampinas, SP.

DEIT OS, R. A. Ensino médio eprofissional eseusvínculoscom OBID/BIRD : osmotivosfinanceiros eas razões ideológicas da política educacional. C ascavel-PR: Edunioeste, 2001.

FIGU EIRED O , I. M . Z. D esenvolvimento, gl obalização e políticas sociais. um exame das determinações contextuais dos projetos de reforma da educação eda saúdebrasileiras daúltima década. 2006. Tese(D outorado em Educação). FaculdadedeEducação. U niversidadeEstadual deCampinas- U nicamp, Campinas, SP.

GON ÇALVES, R.; PO M AR, V. O Brasil endividado. Como anossa dívida externa aumentou mais de 100 bilhões dedólares nos anos 90. São Paulo: Editora Perseu Abramo, 2001.

GO N ZALEZ, M . J. F. etal. 0 Brasil eoBanco M undial: um diagnóstico das relaçõeseconômicas: 1949-1989. Rio deJ aneiro: I PEA/SEPLAN , 1990.

LEH ER, R. D a ideologia do desenvolvimento à ideologia da gl obalização: a educação como estratégia do Banco M undial para "alívio" da pobreza. 1998. Tese(D outorado em Educação). FaculdadedeEducação - U niversidade de São Paulo, São Paulo, SP.

LICH TEN SZT EJN , S.; BAER, M . Fundo M onetário Internacional eBanco M undial: estratégias e políticas do poder financeiro. Tradução de: N athan Giraldi. São Paulo: Brasiliense, 1987.

M CN AM ARA, R. S. O bjetivos del Banco M undial en relación con el crecimiento económico. Centro deEstudios M onetarios Latinoamericanos. Boleín. V. XXV, n.1, ene-feb. 1979.

N AGEL, L. H . O conhecimento a serviço do desenvolvimento: Uma revolução "conceitual" e prática. (mimeo). 2000.

N O GU EIRA, F. M . G. Ajuda externa para a educação brasileira: da USAID ao Banco M undial. C ascavel: Edunioeste, 1999.

O M S/U N ICEF. D EC LARAÇÃO DE ALM A-ATA. Conferência Internacional sobreAtenção Primária em Saúde. U RSS, 1978. Editado pelo D epartamento deI nformação eEducação. BEM FAM - SociedadeC ivil Bem-Estar Famíliano Brasil.

SILVA, M. A. da. Intervenção e consenti mento: a política educacional do Banco M undial. Campinas, SP: AutoresAssociados/ São Paulo: FAPESP, 2002.

SO ARES, L. T. Ajusteneoliberal edesajustesocial na América Latina. Petrópolis, Rio deJ aneiro: Vozes, 2001.

SO ARES, L. T. O scustossociais do ajusteneoliberal na América Latina. São Paulo: Cortez, 2002.

TAVARES, M . C.; FIO RI, J. L. (D es)Ajustegl obal emodernização conservadora. Rio dejaneiro: PazeTerra, 1993.

TEIXEIRA, A . 0 ajusteimpossível: um estudo sobre a desestruturação da ordem econômica mundial e seu impacto sobre o Brasil. 1993. Tese (D outorado em Economia) Instituto de Economia- UniversidadeEstadual deCampinas, Campinas,SP.

Recebido em 22 demarço de 2007 eaprovado em 21 desetembro de 2007. 